\title{
The Research on the Enterprise Price Mechanism from the Perspective of Game Logic
}

\author{
Gao Ai-hua \\ School of Continuing Education, Yanshan University, Qinhuangdao, China
}

\section{Email address:}

gaoaihua@ysu.edu.cn

\section{To cite this article:}

Gao Ai-hua. The Research on the Enterprise Price Mechanism from the Perspective of Game Logic. International Journal of Business and Economics Research. Vol. 6, No. 5, 2017, pp. 111-114. doi: 10.11648/j.ijber.20170605.14

Received: February 23, 2017; Accepted: September 8, 2017; Published: October 28, 2017

\begin{abstract}
With the increasing competition of market economy, the development of enterprises must establish a reasonable price mechanism. This article from the perspective of game logic: the game under the state of free competition among enterprises is the game of rational people to maximize the benefits, in order to achieve the purpose of price mechanism is often taken prisoner's dilemma model; dynamic game logic analysis of enterprise development, in cooperation with other enterprise's price strategy; government regulation is necessary to repair the price mechanism of market competition situation.
\end{abstract}

Keywords: Game Logic, Enterprise Development, Price Mechanism

\section{Introduction}

Game logic is the logic of how rational actors or participants choose strategies or how to act in the process of interaction." The application of [1] logic and the mutual penetration of the game, we know that the game theory has been used in many aspects of the practice of the market, such as sales, pricing, bidding, financing and many other aspects. Some theoretical and logical analysis methods of game theory and fusion, two person game process for the most simple, each individual must be on the other side of the strategy were estimated by logical reasoning, analysis of different effects, finally obtains the optimal strategy for their own benefit. The object of the study of game logic is the reasoning process of the interaction of "rational" decision subject. Game theory is an important method to analyze the competitive situation of enterprises in the market. Modern enterprises are in a constantly changing environment. In order to survive and develop, enterprises need to deal with the price pressure of competitors. In this paper, the method of game logic is used to analyze and discuss how to use the correct price strategy in order to make the enterprise be in a favorable position in the market competition. As a traditional marketing strategy, price competition strategy still plays an important role in the modern market competition. However, some enterprises in the use of this competitive strategy. But often fail to achieve the desired effect. Therefore, it is of great significance for the development of enterprises to analyze the price competition and find out the concrete countermeasures from the perspective of game theory.

\section{The Situation of Price Competition in Chinese Enterprises}

With the strengthening of the degree of marketization, enterprises through continuous reform and development of self-management, self financing is the main business

Must feature. The competition between enterprises in the same industry to compete for the market and expand the share is more and more intense

Fierce competition:

1 , in the marketing mix factors, the price is measurable, clear and the same unit, and to lower prices. The challenge to the competitor is faster than that of other factors. This allows the seller to think more about price competition, resulting in. An enterprise first price reduction. Competitors in order to maintain their market share, so the use of price follow-up led to the entire industry price competition situation.

2 , from the product market characteristics of goods with strong convergence. China's commodity structure, low valueadded goods are still. A large proportion of such goods generally have a strong homogeneity and substitutability, to distinguish between the tools of competition is the price. And 
consumers are extremely sensitive to the price, in order to beat the competition, only competing price.

3 , the rapid growth of production capacity competition, the industry's self regulatory capacity is weak. And the industry in which the enterprise is unable to play the role of price supervision and coordination. In this case, each company will choose their own more favorable price strategy, the result is the price competition caused by the industry.

4 , the enterprise's innovation ability is weak. Innovation is the soul of the enterprise, only constant innovation can bring huge profits to the enterprise. At present, China's enterprises are generally weak in the ability to innovate, in product development, marketing strategy, business management and other aspects of the existence of a simple imitation. By means of price cuts to combat competitors, while companies continue to reduce prices, leading to a reduction in corporate profits, there is no ability to invest a lot of money to develop products and innovation in other areas.

\section{The Prisoner's Dilemma and Uncertainty of Enterprise Cooperation}

Although the phenomenon of win-win between enterprises is very common, but there is also a lack of win-win between enterprises. In the competition of enterprises, the instability of cooperation can be explained by the classical model of "prisoner's dilemma" in game theory. The classic prisoner's dilemma is described as follows: the police arrested two suspects, but there was not enough evidence to accuse the two. The police then separately imprisoned suspects, were met and two people, and to provide the following options: both pleaded guilty and the prosecution to testify each other (related to the term "betrayal" of each other) or silent (related term "cooperation"). If one chooses to betray and the other chooses to cooperate, the person will be released immediately, and the partner will be sentenced to prison for 10 years. If two people have chosen to cooperate, then the same person sentenced to six months in prison for the two. If two people betray each other, then the two men also sentenced to prison for 2 years. We can use a form to express in table 1:

Table 1. The prisoner's dilemma game logic model.

\begin{tabular}{lll}
\hline A silence (cooperation) & A confession (against) & \\
\hline \multirow{2}{*}{ B silence (cooperation) } & two people with the & A release; serving for \\
& same term half & 10 years \\
B plea (against) & A serving 10 years; B & two people with \\
& released & serving 2 years \\
\hline
\end{tabular}

If you are one of them, consider only how much you can do to minimize your prison years I believe most. People will choose to "betrayal", there are too many reasons for people to choose to betray, for example, some people believe that the other party will betray you, and You don't want to choose to work together for 10 years, so you choose to betray and serve a sentence of 2 years. His reason is very good for him Points, but we also need to consider another situation, that is, B firmly believe that a will not betray him, then B should choose. B or should choose to betray, because B choose betrayal can be released immediately, and B choose to cooperate also need to serve six months. In this. Under these circumstances, no matter what the choice of a, B is always better than the choice of cooperation, then we say that the betrayal is B. Advantage strategy". Whether it's the fact of the experiment or the simple analysis, it tells us that betrayal is the best choice for everyone.

So in the end two people will choose to betray, and the same term of imprisonment for 2 years, this is the result of the prisoner's dilemma. [3], The cooperation between enterprises is based on the gains and losses of interestsThe interests of the big fight, is unstable. It is assumed that the basic structure of the game between the two firms is as shown in the table 2, The price of each half of the market and earn 2000 yuan; if both sides take high prices, then the same half of the market, the price, so to earn 3000 yuan, finally, if two different pricing, price market revenue was 0 , while the low price 4000 yuan. as shown in table 2 :

Table 2. A and B enterprises price game matrix.

\begin{tabular}{lll}
\hline B enterprise & & \\
\hline Low prices & High prices & \\
\hline A enterprise Low prices & 2000,2000 & 4000,0 \\
High prices & 0,4000 & 3000,3000 \\
\hline
\end{tabular}

The enterprise game shown in the above table is a prisoner's dilemma model, "low price" is the dominant strategy of both sides, although the "high price" can make them more profitable. But as mentioned earlier, the store actually takes third price strategies: the lowest price for its consumers.

Now consider what it would be like if companies were allowed to choose high prices, low prices, and low prices. "The promise of the lowest price strategy" allows companies to take "high prices", but promises to be as low as any competitor. If you also take a "high price", "promise the lowest price" will benefit from it; if the opponent to take the "low price", it will not suffer any loss. We see the new game payment structure shown in table 3, take a "low", and the other to take a "combination of promise low price" strategy, with both sides to take the "low-cost" combination is equivalent; and the other to take a "high price" and the other party to take the combination of promise low price "strategy (or both sides of the" combined promised low "strategy), with both sides to take the" high "combination is equivalent. as shown in table 3:

Table 3. The new strategy of $A$ and $B$ enterprises with game matrix.

\begin{tabular}{lllr}
\hline B enterprise & & \\
\hline Low prices & High prices & Promise the lowest price \\
\hline Low prices & 2000,2000 & 4000,0 & 2000,2000 \\
A enterprise & & & \\
High prices & 0,4000 & 3000,3000 & 3000,3000 \\
Promise the lowest price & 2000,2000 & 3000,3000 & 3000,3000 \\
\hline
\end{tabular}

Using the standard analysis method and action game, the "low" promised "high price", weakly dominates once 
removed "high", "low" to "promise the lowest price" is if the inferior Nash equilibrium strategy, finally the result is that both sides have taken "promise the lowest price" strategy. Balance, the two sides get 3000 yuan, this payment and the original game both sides to take the high price of the same. The promise of the lowest price strategy to solve the problem when the enterprise can only choose the "high price" and "low price" of the prisoner's dilemma, for both sides to find a compromise solution to the problem.

In fact, the "lowest price" strategy is the role of punishment mechanism. Although the A enterprise's lowest price strategy began to take a high price, but it promises to be cheap, so greatly reduced the B to take advantage of the low price. In addition, the use of low-cost B promised to harm the interests of A companies themselves, because he must accept the low price of low income. Therefore, as long as someone betrayed, "promise the lowest price" strategy will punish both.

The proof of the fact that such a "minimum price" strategy exists, but not so much, and some studies have found that there are such strategies in low priced markets. However, the results of all consumer alert, while businesses to compete in the name of "promise the lowest" strategy, but they are all taken the final results of this strategy, is more favorable for businesses, but will be serious damage to the interests of consumers. [4]

By using the theory of prisoner's dilemma in the logical analysis of the price competition behavior between enterprises in our country are analyzed. Their utility depends not only on their own choice, but also depends on other business choice, the choice of enterprise is the optimal choice function of other enterprises. The game logic analysis method to change personal isolation strategy based on traditional economic analysis that analyze the interaction and influence while focusing on economic activities in more than one interest behavior, which helps enterprises in the fierce competition in a more thorough analysis of the decisionmaking behavior of competitors, in order to guide business decisions.

\section{The Dynamic Game and Firm Commitment Strategy}

The types of games are divided into static game and dynamic game. In the static game, the decision maker must make its own strategy. At the same time, the enterprises involved in the action game should take into account how the opponent will act, and to understand how the opponent in the timing of their own actions. The first actors will provide new information for actors, actors and adjusted according to their own strategy, therefore, the first actors in the selection of their own actions when considering the influence of their choice of actors and the influence on the final results. All participants must consider: if I do. How will my opponent react. Whether the interests of the participants are completely conflict, in reality, most of the games have the pressure of competition and cooperation

The key is to deal with the relationship between competition and cooperation. Participants know that failure is not good for everyone. Suppose there are two. Competitive enterprises, and they set the price of their respective products. Therefore, price is the strategy in the competition game. enterprise. The goal is to set a reasonable price in order to maximize profits, that is, the pursuit of the game to maximize the payment. Right now. Only two kinds of prices are available: a high price of $\$ 26$ and a low price of $\$ 20$. If there is no strategic action. Game equilibrium is both the low price of $\$ 20$, but the 26 yuan price will get higher pay, as shown in table 4:

Table 4. $A$ and $B$ enterprises pricing game.

\begin{tabular}{llll}
\hline A enterprise & & & \\
\hline & 20(Low ) & 26(High) & \\
\hline A enterprise & 20(Low ) & 288,288 & 360,216 \\
& 26(High) & 216,360 & 324,324 \\
\hline
\end{tabular}

The payoff matrix shows the profits of each firm. If a party makes a credible commitment; if you take a high price, I will take a high price. Then the two will be the result of cooperation. For example, if the B enterprises have made the promise, A companies will know the price of 26 yuan will reach a win-win situation, the creation of the table right under the case payment; and the choice of 20 yuan will make $\mathrm{B}$ enterprise the same as before, also choose the price of 20 yuan, has been left on lattice pay. Between these two, A companies are more willing to choose the former, so will choose high.

At this time, the most feasible way for B companies is to develop a reputation for keeping credit in business. In a repetitive relationship, the promise will work, as a breach of promise could undermine future cooperation. In essence, a continuous relationship indicates that the game is divided into many small parts, in which the benefits of breaking promises are much less than their losses. In this kind of game, the cost of future cooperation will change the price of fraud.

\section{The Relationship Between the Market Price Mechanism and Government Regulation in Enterprise Game}

The role of the government in the economic field requires the government to intervene appropriately to make up for the defects of the market. The government's price management is actually the repair of the market price mechanism. The government through the management and give full play to the basic role of market price in the rational allocation of resources, improve the modern market system, to ensure that the price can reflect the market supply and demand changes and the scarcity of resources, resource oriented transfer signal correctly to the society, reasonable adjustment of various aspects of the economic benefits to the enterprise, to optimize the allocation of resources and dynamic pressure; 
the overall goal of government function and the national economy price is consistent, by strengthening and improving macro-control, correction, make up the defect of the market price, to ensure the coordinated development of social and economic stability. The government adopted the following measures to implement price management:

First, strengthen and improve price regulation, and strive to maintain the basic stability of the overall price level. The government is the main content of price management for the price of macro regulation, through the establishment of sound price monitoring, early warning aircraft to strengthen price trend analysis, correctly grasp the economic situation, in order to effectively control the overall price level, the economic benign operation. At present, the price adjustment fund system, temporary intervention and other measures to regulate and control is also relatively simple, to further improve the price of the macro-control system, rich regulatory measures and increase the intensity of regulation.

Second, the correct performance of the functions of price management. Giving full play to the role of market mechanism is the requirement of the development of modern market economy. Reform needs to further enliven the market, the opening price, but the price liberalization is not equal to the price does not need to manage and let things drift. Modern market economy is a market economy with limited freedom. Therefore, the modern market economy needs government intervention and macro control. The functions of government departments in the modern market economy:

1, the government should set the framework for the effective operation of the market price mechanism. The effective operation of the market price mechanism depends on the institutional framework from the government through the establishment of price policy, macro-control measures, focus on the practice of constantly strengthening legislation and corresponding laws and regulations and regulations from to maintain the market order of fair competition from the effective operation of the market price mechanism.

2 , so that after the liberalization of the market to achieve rather than chaos, live and orderly, the price behavior of the production operators continue to be standardized. The government will strengthen the price of administrative law enforcement, in accordance with the laws and regulations of the price of the market price behavior of the main body of supervision and adjudication, to ensure that the price of the game rules are effectively observed and normal operation. It is important to note that the price administrative department to intervene to solve the market price problems, should pay attention to the timing and intensity, and focus on the use of methods and means in accordance with the requirements of the market economy, we must focus on the overall development, support and promote fair, open and legal market competition environment.

\section{Conclusion}

In short, the enterprise in the increasingly mature market economy situation, the price mechanism increasingly occupy an important position in the development of competition, using some theories and models in the game logic, analysis of price mechanism of business transactions, insight into the hidden rights practice and multiple effects, and government intervention is the necessary revision and supplement. Although the competitive commodity prices are mainly determined by the commodity value and the market, but the use of game logic, contribute to a more scientific analysis of the price mechanism, still has a certain effect on the price management between enterprises, hope the relevant departments to get enlightenment from the game logic theory.

\section{Foundation Item}

Project supported by the science and technology research and development program of Hebei province (project number: 134576239).

\section{Name of the Project}

The competition of Hebei private enterprises from the perspective of game logic.

\section{References}

[1] Zhang Feng. Application of game logic. Journal of Beifang Univesity of Nationality, 2010 (4): (133-136).

[2] Zhang Shixin. Analysis on the price competition strategy under the game. mall modernization, 2007. 17 (100-11).

[3] ice ocean http://www.guokr.com/post/2860/

[4] Victoria Song's game logic analysis of enterprise competition [D]. Master Thesis of Yanshan University. 2005. 6.

[5] Ni Jingying. market price mechanism and Countermeasures. 2005. 6 .

[6] Li Fangfei, Sun Jitao. Stability and stabilization of multivalued logical network. Nonlinear Analy-sis: Real World Applications [J], 2011, 12: 3701-3712.

[7] Qi H, Cheng D, Dong H. On Networked Evolutionary Games Part 1: Formulation [J]. Ifac Proceedings Volumes, 2014, 47(3): 275-280.

[8] Cheng D, He F, Xu T. On Networked Evolutionary Games Part 2: Dynamics and Control [J]. Ifac Proceedings Volumes, 2014, 47(3): 281-286.

[9] Cheng D, Qi H, Li Z, et al. Stability and stabilization of Boolean networks [J]. International Journal of Robust \& Nonlinear Control, 2011, 21(2): 134-156.

[10] Cheng D, Qi H. Controllability and observability of Boolean control networks $[\mathrm{J}]$. Control Theory \& Applications, 2009, 45(7): 1659-1667.

[11] Fu S, Wang Y. Biased imitation in coupled evolutionary games [C], Control Conference. IEEE, 2015: 9134-9139. 